\title{
AHP approach for supplier evaluation and selection in a steel manufacturing company
}

Farzad Tahriri; M. Rasid Osman; Aidy Ali; Rosnah Mohd Yusuff; Alireza Esfandiary

University Putra Malaysia (MALASYA)

farzad_tabriri@hotmail.com; rasid@,eng.upm.my; aidy@eng.upm.my;rosnah@,eng.upm.my;

ar62e@yahoo.com

Received October 2008

Accepted December 2008

Abstract: Supplier selection is one of the most critical activities of purchasing management in supply chain. Supplier selection is a complex problem involving qualitative and quantitative multi-criteria. A trade-off between these tangible and intangible factors is essential in selecting the best supplier. The work incorporates AHP in choosing the best suppliers. The results suggest that AHP process makes it possible to introduce the optimum order quantities among the selected suppliers so that the Total Value of Purchasing (TVP) becomes maximum. In this work, an AHP-based supplier selection model is formulated and then applied to a real case study for a steel manufacturing company in Malaysia. The use of the proposed model indicates that it can be applied to improve and assist decision making to resolve the supplier selection problem in choosing the optimal supplier combination. The work represents the systematic identification of the important criteria for supplier selection process. In addition, the results exhibit the application of development of a multi-criteria decision model for evaluation and selection of suppliers with proposed AHP model, which by scoring the performance of suppliers is able to reduce the time taken to select a vendor.

Keywords: Analytic Hierarchy Process (AHP), supplier selection, Total Value of Purchasing (TVP) 


\section{Introduction}

In most industries the cost of raw materials and component parts constitutes the main cost of a product, such that in some cases it can account for up to $70 \%$ (Ghodsypour \& O'Brien, 1998). In such circumstances decision making of purchasing management can play a key role in cost reduction. In today's highly competitive environment, an effective supplier selection process is very important to the success of any manufacturing organization (Liu \& Hai, 2005).

The particular scheme discussed in this paper, known as the $A B C$, is intended for Malaysia's steel industry. Business activities and services of $A B C$ steel company provide both mechanical and structural steel design, engineering, procurement, fabrication, installation and commissioning services for Steel mills such as: Limekilns, Hydration \& PCC plants, power plants, cement plant \& storage tanks, chemical and industrial plants, piping works, paints shop, machinery and plant installation, customized design items \& maintenance, commercial building steel structure \& roof steel structures and steel bridges. While the majority of ABC's projects are in Malaysia, $A B C$ also supplies and fabricates for projects in other countries such as Indonesia, Singapore, Papua New Guinea.

Selecting the suitable supplier is always a difficult task for buyers. Suppliers have varied strengths and weaknesses, which require careful assessment by the purchasers before ranking, can be given to them.

The vendor selection process would be simple if only one criterion was used in the decision making process. However in many situations, purchasers have to take account of a range of criteria in making their decisions. If several criteria are used then it is necessary to determine how far each criterion influences the decision making process, whether all are to be equally weighted or whether the influence varies accordingly to the type of criteria (Yahya \& Kingsman, 1999). The ABC model development for steel manufacturing company for selection of vendors has to be done not only to ensure benefits to the purchaser customers but also to order raw materials on account of the following reasons: (1) Huge variety of finished products, and thus great need for raw materials. (2) The large number of projects in process. (3) The huge fluctuations in price for raw materials such as: mild steel sheets, stainless steel and UB steel. (4) The large number of suppliers providing varieties in qualitative and quantitative criteria. 
Supplier selection problem is a group Multiple Criteria Decision-Making (MCDM) out of which quantities criteria has been considered for supplier selection in the previous and existing decision models so far (Chen-Tung, Ching-Torng \& Huanget, 2006). In Multiple Criteria Decision-Making (MCDM), a problem is affected by several conflicting factors in supplying selection, for which a purchasing manager must analyze the trade off among the several criteria. MCDM techniques support the decision-makers (DMs) in evaluating a set of alternatives. Depending upon the purchasing situations, criteria have varying importance and there is a need to weigh them (Dulmin \& Mininno, 2003).

For Multiple Criteria Decision-Making (MCDM) problem of $A B C$ steel manufacturing company a unique and suitable method is needed to facilitate the supplier selection and consequently provide the company with a proper and economical system for ordering raw materials.

The analytic hierarchy process (AHP) has found widespread application in decisionmaking problems, involving multiple criteria in systems of many levels (Liu \& Hai, 2005). This method has the ability to structure complex, multi-person, multiattribute, and multi-period problem hierarchically (Yusuff, PohYee \& Hashmi, 2001). The AHP can be very useful in involving several decision-makers with different conflicting objectives to arrive at a consensus decision (Tam \& Tummala, 2001). The AHP method is identified to assist in decision making to resolve the supplier selection problem in choosing the optimal supplier combination ( $\mathrm{Yu} \&$ Jing, 2004). Considering the existing problems in the company initiating from incorrect supplier selection, owing to the human mistakes in judging the raw materials, or paying too much attention to one factor only, such as price, cost and other similar and unexpected problems, the AHP model is highly recommended to handle the supplier selection more accurately in order to alleviate, or better yet, eradicate the mistakes in this line.

\section{Supplier selection criteria}

One major aspect of the purchasing function is supplier selection criteria. The analysis of criteria for selection and measuring the performance of suppliers has been the focus of attention for many scientists and purchasing practitioners since 1960 's. In the mid 1960's, researchers were developing performance criteria upon which potential suppliers could be evaluated. Dickson (1966) firstly performed an 
extensive study to determine, identify and analyze what criteria were used in the selection of a firm as a supplier. Dickson's (1966) study was based on a questionnaire sent to 273 purchasing agents and managers selected from the membership list of the National Association of Purchasing Managers. The list included purchasing agents and managers from the United States and Canada, which was a total of 170 (62.3 of Dickson's study) regarding the importance of 23 criteria for supplier (vendor) selection. Dickson asked the respondents to assess the importance of each criterion on a five point scale of: extreme, considerable, average, slight and of no importance. Based on respondents' reply "quality" is the most important criterion followed by "delivery" and "performance history". Weber, Current and Benton (1991) presented a classification of all the articles published since 1966 according to the treated criteria. Based on 74 papers, the outputs observe that Price, Delivery, Quality and Production capacity and location were the criteria most often treated in the literature.

According to Weber, Current and Benton (1991), the review of the articles about Supplier selection (SS) between 1966 and 1991 was investigated and in related study, Zhang, Lei, Cao and Ng (2003) collected 49 articles between 1991 and 2003, was a comprehensive classification of supplier selections published. The study of Zhang et al. was done based on the Weber, Current and Benton (1991) study and the 23 criteria of Dickson (1966) study. The study concluded that net price, quality, and delivery were the most important supplier selection criteria. As concluded from three different studies, price is the number one selection factor, replacing Dickson (1966) number one ranked quality criteria.

In addition to the well-noted research studies of Dickson (1966), Weber, Current and Benton (1991) and Zhang, Lei, Cao and Ng (2003), other researchers have also recently begun discussing the importance of additional supplier selection criteria, not mentioned in the above studies. Another study by Tullous and Munson (1991), which sampled eighty (80) manufacturing firms, discovered that quality, price, technical service, delivery, reliability, and lead time were among the most important selection factors. The definitions of Dickson (1966) 23 criteria have been expanded and some new criteria were developed with the growth of new business needs. The review performed by Bross \& Zhao (2004) study concluded that the most valuable supplier selection criteria were cost, quality, service, relationship, and organization. 
Davidrajuh (2000) reviewed some studies which emphasize the important criteria and their invariability. While a number of supplier selection criteria studies have been conducted over the years, Dickson (1966), Weber, Current and Benton (1991) and Zhang, Lei, Cao and $\mathrm{Ng}$ (2003) are still recognized as the most common, and cited as the most comprehensive studies done on selection criteria.

\subsection{Supplier selection with AHP method}

Analytic Hierarchy Process (AHP), since its invention, has been a tool at the hands of decision makers and researchers, and it is one of the most widely used multiple criteria decision-making tools (Omkarprasad \& Kumar, 2006). Many outstanding works have been published based on AHP. They include applications of AHP in different fields such as planning, selecting best alternative, resource allocations, resolving conflict, optimization, etc., as well as numerical extensions of AHP (Vargas, 1990). Among applications of AHP method for the field of selecting the best alternative, the following publications are specified to supplier selection. Ghodsupour and O'Brion (1998) studied the conflicts between two tangible and intangible factors, based on AHP method, i.e. qualitative and quantitative, in order to choose the best suppliers. They integrated AHP and Linear Programming to consider both tangible and intangible factors in choosing the best suppliers and placed the optimum order quantities among them such that by using integrated AHP and LP the Total Value of Purchasing (TVP) becomes maximum. This model can apply to supplier selection with or without capacity constraints.

Yahya and Kingsman (1990) used Saaty's (1980) AHP method to determine priority in selecting suppliers. The authors applied vendor rating in supplier selection and in deciding how to allocate business, as well as in determining where scarce development effort is applied. This study is performed for a government sponsored entrepreneur development program in Malaysia. The particular Umbrella Scheme of Malaysia's furniture industry was applied using this method. The selection of vendors in Scheme Company has to be done not only to ensure benefits to the purchasers but also to develop the vendors. The multiple and conflicting objectives, both getting good quality furniture companies improve their operations, imply that the criteria to use in selecting vendors might be different than that for normal commercial purchasing of goods. Given the need to identify the strengths and weakness of vendors for the development purposes of the scheme, a vendor rating system is essential and cannot be avoided. Akarte (2001) used AHP to select the 
best casting suppliers from the group of evaluated suppliers. The evaluation procedure took care of about 18 different criteria. These were segregated into four groups namely: product development capability, manufacturing capability, quality capability, and cost and delivery. Out of 18 different criteria, six were of objective and twelve were of subjective types. The evaluation method of this model is based on relative performance measure for each supplier for subjective (qualitative) criteria which is obtained by quantifying the ratings expressed in quantitative terms. The supplier who has the maximum score is selected.

Tam and Tummala (2001) have used AHP in vendor selection of a telecommunication system, which is a complex, multi-person, multi-criteria decision problem. The authors have found AHP to be very useful in involving several decision makers with different conflicting objectives to arrive at a consensus decision. The decision process, as a result, is systematic and reduces time to select the vendor. Handfield, Walton and Sroufe (2002) studied Environmental criteria to supplier assessment by transforming purchasing in to a more strategic function. The authors integrated the environmental issues to make purchasing managers introduce dimensions in to their decisions, for which both qualitative and quantitative factors complicate the problem. By applying AHP in environmental criteria to supplier assessment, the authors were able to solve the above problem. AHP method may integrate environmental criteria in the sourcing decision process for supplier selection.

In order to make a company unique, Yu and Jing (2004) developed a new decision model to choose the optimal supplier combination for Tian Jin Electric Construction Company. According to the previous research by Tam and Tummala (2001), Yu and Jing (2004) found out, through research, that trust between suppliers and buyers is the best criterion for selecting optimal supplier which reduces the cost, by using AHP and Linear Programming (LP). The authors established trust for Tian Jin Electric Construction Company. Through research, the authors came up with the fact that quality criteria can be more influential in supplier selection than quantity, although other criteria such as: cost, quality and delivery were used and trust was focused on as important criteria for supplier selection. Liu and Hai (2005) studied supplier selection by integrating a collaborative purchasing program. The authors came up with a new approach, based on the use of Saaty's (1980) AHP method. This system, called voting AHP (VAHP), provides a simpler method than AHP, but does not lose the systematic approach of deriving the weights and sorting 
performance of suppliers. (VAPH) allows the purchasing manager to generate noninferior purchasing options and systematically analyze the inherent trade-offs among the relevant criteria.

\section{Model development}

The objectives of this works are to develop AHP method for supplier selection. The methodology of this work has been adopted from Yahya and Kingsman (1999), Tam and Tummala (2001) and Yu and Jing (2004). In order to comply with collecting quantitative and qualitative data for AHP supplier selection model that could be applied by the steel manufacturing company a six steps approach was performed to insure successful implementation as follows:

\subsection{Step 1: Define criteria for supplier selection}

The first step in any supplier rating procedure is to establish the criteria to be used for assessing the supplier. To comply with the criteria for supplier selection and their importance required data were collected based on the consideration of literature. Based on considering the studies of Dickson (1966); Weber, Current and Benton (1991); Dyer, Cho and Chu (1996); Li, Fun \& Hung (1997); Ghodsupour and O'Brion (1998); Yahya and Kingsman (1999); Tam and Tummala (2001); Handfield, Walton and Sroufe (2002); Zhang, Lei, Cao and Ng (2003); Bello (2003); Yu and Jing (2004); Liu and Hai (2005); Amid, Ghodsypour and O'brien. (2006); Przewosnik, Smeja and Tenschertet (2006) and Chen-Tung, Ching-Torng and Huanget (2006), thirteen important criteria were selected. After defining the criteria for selecting the supplier, the first structured interview was designed based on the input received; an additional criterion were added such that the respondents were asked to identify the importance of each criterion by using numbers from 1 to 9. In order to identify relevant criteria, the respondents were asked to rate each factor using the four-point scale of "Not important (1 to 3)", "Some-what important (4 to 5)", "Important (6 to 7)" and "Very important (8 to 9)" (Tam and Tummala, 2001). This structured interview consisted of: the general characteristics of the company, model or the type of method used for supplier selection, and providing thirteen items indicating the best selected criteria for supplier selection.

Before start of the research, according to the AHP method, the structured interview was filled out by a related specialist (the procurement manager) to evaluate the 
criteria. Interviews were conducted with three members of the $A B C$ Engineering Steel Company namely, the two project managers and a purchasing manager represented in order by (R1), (R2) and (R3) respectively as shown in (Figure 1). This test was carried out, on account of its importance in supplier selection and upgrading the decision making accuracy. The resulting structured interviews were mailed to the selected respondents. The results of the case study are summarized in Figure1. The respondents were requested to include any additional criteria that seemed important, in the structured interviews, and identify their level of importance. Having received the inputs of the respondents, the criteria were identified and averaged. In addition, the presence of too many criteria makes the pair-wise comparisons in evaluating suppliers a difficult and time consuming process. To overcome these problems, the cut-off value to reduce the number of criteria to a few is desirable Tam and Tummala (2001). In order to select the most important criteria, it was intended to accept the criteria with average above 7. Finally, the effective extremely important criteria such as quality, delivery, direct cost, trust, financial and management and organization were selected at level (2) in supplier selection model (The goals factor in Level (1) for supplier selection model is to select the best overall supplier).

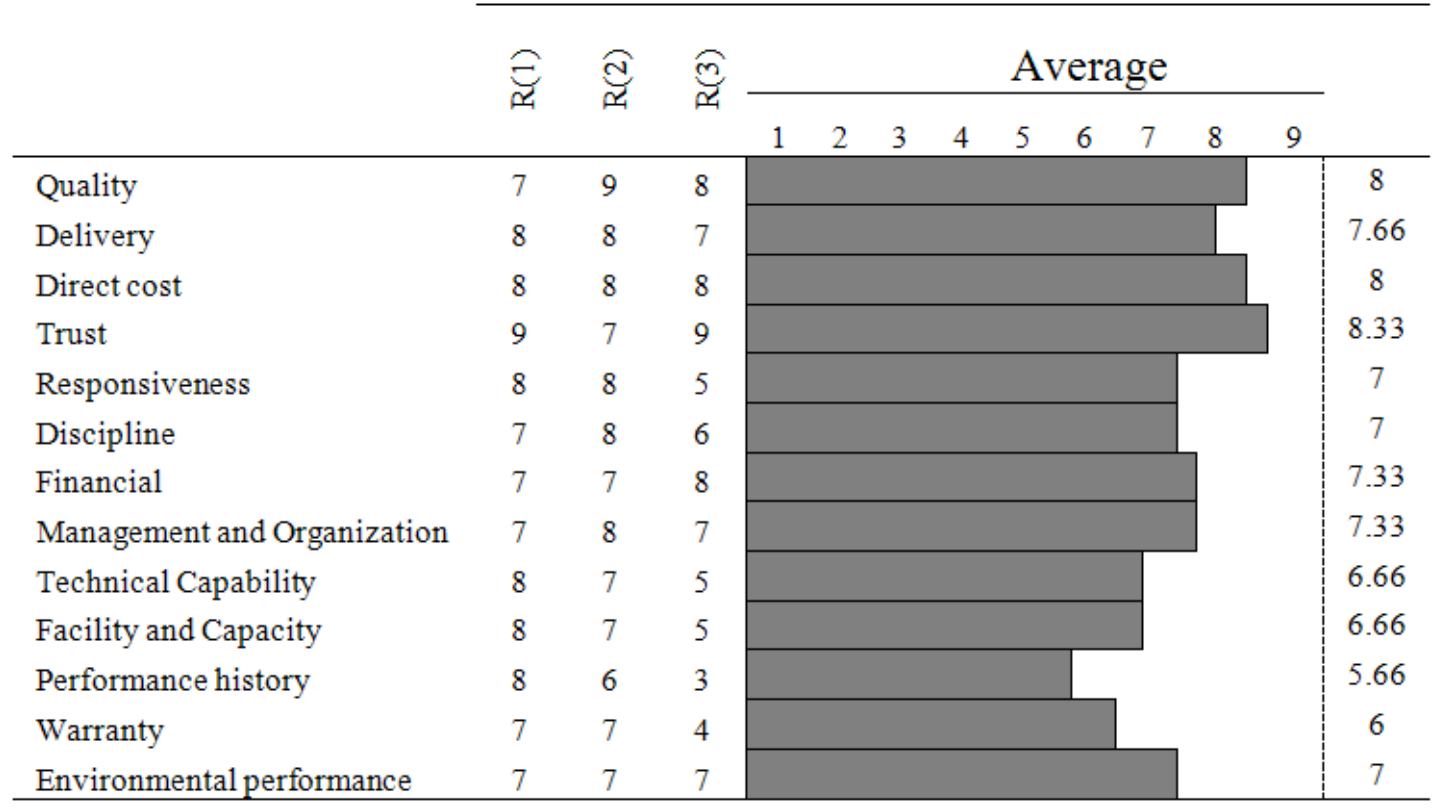

Figure 1. "Factors affecting the selection of a Steel manufacturing company". 


\subsection{Step 2: Define sub criteria and sub sub-criteria for supplier selection}

In this step, the definition of the sub criteria and sub sub-criteria has been done for supplier selection based on the eight important criteria selected as the results of previous step with the consideration of literature. Design and modification of identified sub and sub-criteria, also respondents, selection of the second structured interview, have been done similar to the first step.

By using the second structured interview, it becomes possible to find sub and sub sub-criteria. On account of the problems involved in sending the questionnaires to the proper authorities and getting their response, as well as to minimize the efforts, second structured interviews were applied to cover two goals.

- To find sub-criteria and sub sub-criteria.

- To weight and compare pair-wise for all criteria, sub-criteria and sub subcriteria.

After receiving the inputs of the respondents, the criteria were identified and averaged. Nine sub criteria and thirty sub sub-criteria were selected for levels (3) and (4) in supplier selection model as shown in (Figure 2).

\subsection{Step 3: Structure the hierarchical model}

This phase involves building the AHP hierarchy model and calculating the weights of each levels of supplier selection model. The developed AHP model, based on the identified criteria, sub criteria and sub sub-criteria, contains five levels: the goal, the criteria, sub-criteria, sub-sub criteria and alternatives. (Figure 2) shows an illustrative 5-level hierarchy for the supplier selection problem. The goal of our problem in selecting the supplier for the steel manufacturing company in Malaysia is identified in the first level. The second level (criteria) contains: cost, delivery, quality, management and organization, trust and financial. The third and fourth level of the hierarchy consist 9 sub criteria and 30 sub sub-criteria, which were identified in previous section. The lowest level of the hierarchy contains of the alternatives, namely the different supplier to be evaluated in order to select the best supplier. As shown in (Figure 2), four suppliers were used to represent arbitrarily the ones that the firm wishes to evaluate. The AHP model shown in (Figure 2) is generally applicable to any supplier selection problem of "ABC" steel 
manufacturing company that a team wishes to evaluate, as it covers the critical factors and the related criteria and sub criteria and sub sub-criteria for supplier selection of a steel manufacturing company.

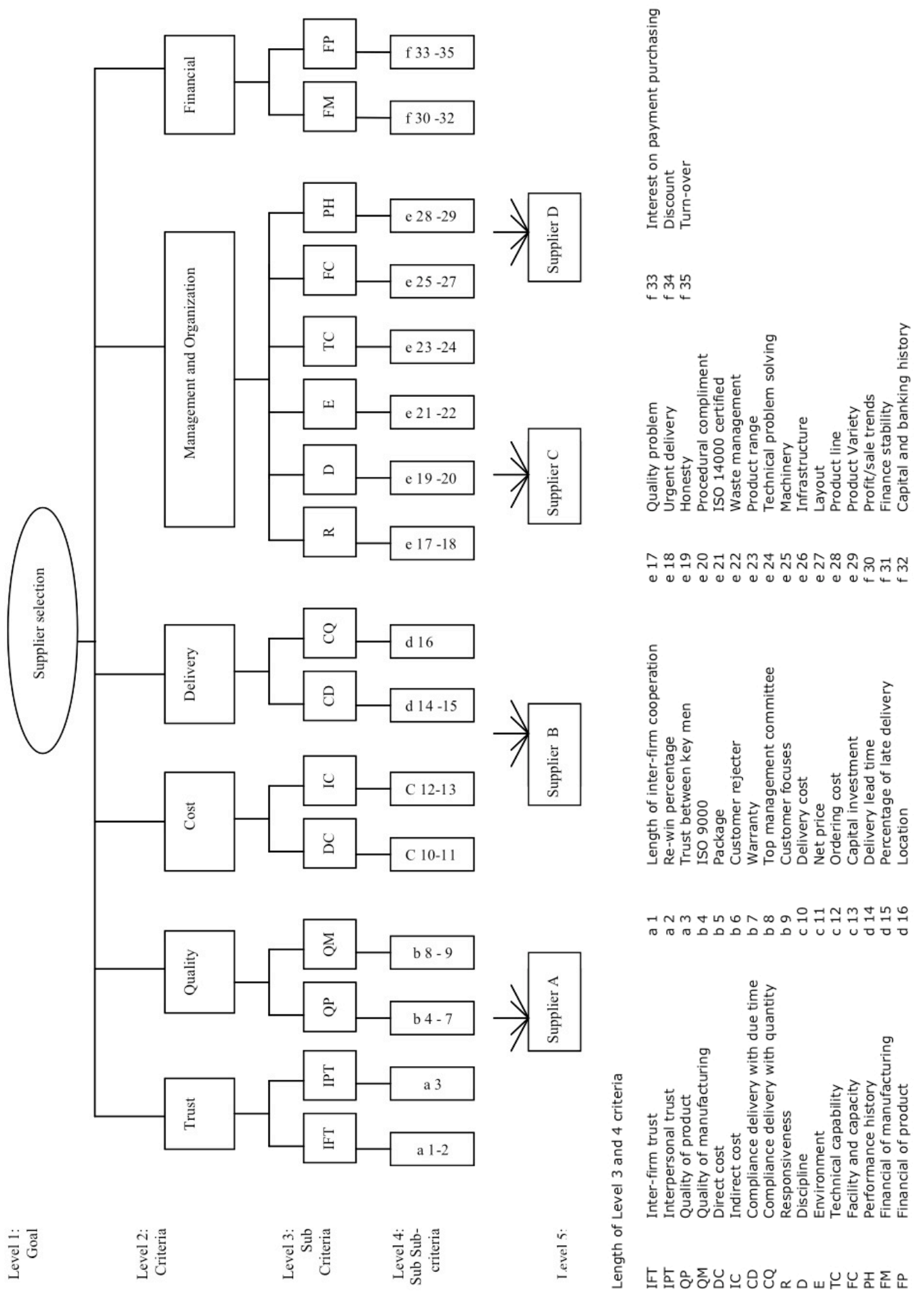

Figure 2 " An illustrative decision hierarchy for supplier selection". 
To complete the model at this stage, the priority weight of each criterion in each level was determined. A second structure, an interview consisting of all factors in each level of the AHP model is used to collect the pair-wise comparison judgments from all evaluation team members. This approach is found to be very useful in collecting data. This determination is performed through using pair-wise comparisons. The function of the pair-wise comparisons is by finding the relative importance of the criteria and sub criteria which is rated by the nine-point scale proposed by Saaty (1980), as shown in Table 1, which indicates the level of relative importance from equal, moderate, strong, very strong, to extreme level by $1,3,5,7$, and 9, respectively. The intermediate values between two adjacent arguments were represented by $2,4,6$, and 8 .

\begin{tabular}{|c|c|}
\hline Verbal judgment or preference & Numerical rating \\
\hline Extremely preferred & 9 \\
Very strongly preferred & 7 \\
Strongly preferred & 5 \\
Moderately preferred & 3 \\
Equally preferred & 1 \\
Intermediate values between two adjacent & $2,4,6$, and 8 \\
judgments ( when compromise is needed) & \\
\hline
\end{tabular}

Table 1. "Measurement scales". Source: Saaty (1980)

Sample of pair-wise comparison matrix shows that the entry for the fourth row and the fourth column gives the importance of that row's criterion relative to the column's criterion as shown in Table 2.

\begin{tabular}{|c|c|c|c|c|}
\hline $\begin{array}{c}\text { Criteria for } \\
\text { Supplier selection }\end{array}$ & C & Q & F & D \\
\hline Cost (C) & 1 & 2 & 5 & 5 \\
\hline Quality (Q) & $1 / 2$ & 1 & 4 & 4 \\
\hline Facility (F) & $1 / 5$ & $1 / 4$ & 1 & 3 \\
\hline Delivery (D) & $1 / 5$ & $1 / 4$ & $1 / 3$ & 1 \\
\hline
\end{tabular}

Table 2. "Example for pair-wise comparison matrix".

Therefore a good performance on cost, the criterion for the first row, is slightly preferred to the one on quality (shown by the value of 2), which is strongly compared to the vendor having good facility and delivery, (shown by the value of 5). A good performance on quality, the criterion for the second row and column, is moderately more important than having good facility and delivery, (shown by the value of 4). Having good facility, the third row criterion is weakly more important than good delivery, (value of 3 ). The decision makers only need to fill in the upper 
half of the comparison matrix because, for example, assuming that the pair-wise comparison of facility to delivery is 3, or equivalently a 3 to 1 ratio, it follows that the pair-wise comparison of delivery to quality is a 1 to 3 ratio, or $1 / 3$. A value of 1 is assigned to the diagonal elements since delivery (row) is equally preferred to delivery (column).

After obtaining the pair-wise judgments as in Table 3, the next step is the computation of a vector of priorities or weighting of elements in the matrix. In terms of matrix algebra, this consists of calculating the "principal vector" (engenvector) of the matrix by adding the members of each column to find the total. In the next step, in order to normalize each column to sum to 1.0 or $100 \%$, divide the elements of that column by the total of the column and sum them up. Finally, add the elements in each resulting row and divide this sum by the number of elements in the row to get the average. The results (principal vectors) are that the attributes have the following approximate priority weights: Cost (0.501), Quality (0.319), Facility (0.089), Delivery (0.089).

\begin{tabular}{|c|c|c|c|c|c|c|}
\hline $\begin{array}{c}\text { Criteria for } \\
\text { supplier selection }\end{array}$ & Average & $\begin{array}{c}\text { Row } \\
\text { Total }\end{array}$ & D & F & Q & C \\
\hline Cost (C) & 0.501 & 2.005 & 0.454 & 0.454 & 0.571 & 0.526 \\
\hline Quality (Q) & 0.319 & 1.274 & 0.363 & 0.363 & 0.285 & 0.263 \\
\hline Facility (F) & 0.089 & 0.356 & 0.090 & 0.090 & 0.071 & 0.105 \\
\hline Delivery (D) & 0.089 & 0.356 & 0.090 & 0.090 & 0.071 & 0.105 \\
\hline TOTAL & 1 & & 1 & 1 & 1 & 1 \\
\hline
\end{tabular}

Table 3. "Normalized matrix of paired comparisons and calculation of priority weights".

The consistency ratio (C.R.) for the comparison above is calculated to determine the acceptance of the priority weighting. The consistency test is one of the essential features of the AHP method which aims to eliminate the possible inconsistency revealed in the criteria weights, through the computation of consistency level of each matrix. The software system called Expert Choice is used to determine the normalized priority weights. The consistency ratio (CR) was used to determine and justify the inconsistency in the pair-wise comparison made by the respondents. Based on Saaty's (1980) empirical suggestion that a C.R. $=0.10$ is acceptable, it is concluded that the foregoing pair-wise comparisons to obtain attribute weights are reasonably consistent. If the $C R$ value is lower than the acceptable value, the weight results are valid and consistent. In contrast, if the CR value is larger than the acceptable value, the matrix results are inconsistent and are exempted for the further analysis. 


\begin{tabular}{|c|c|c|c|}
\hline Trust & $\begin{array}{c}\text { Inter personal } \\
\text { trust }\end{array}$ & $\begin{array}{c}\text { Trust } \\
\text { between key } \\
\text { men }\end{array}$ & $\begin{array}{c}\text { Global } \\
\text { weights }\end{array}$ \\
\hline 0.448 & 0.785 & 1.000 & 0.3517 \\
\hline
\end{tabular}

Table 4a. "Composite priority weights for sub sub-criteria".

\begin{tabular}{|c|c|c|c|c|c|c|}
\hline Criteria & $\begin{array}{c}\text { Local } \\
\text { weights }\end{array}$ & Sub Criteria & $\begin{array}{c}\text { Local } \\
\text { weights }\end{array}$ & Sub sub-criteria & $\begin{array}{c}\text { Local } \\
\text { weights }\end{array}$ & $\begin{array}{c}\text { Global } \\
\text { weights }\end{array}$ \\
\hline \multirow[t]{3}{*}{ Trust } & \multirow[t]{3}{*}{0.448} & $\begin{array}{l}\text { Inter personal } \\
\text { trust }\end{array}$ & 0.785 & Trust between key men & 1.000 & 0.3517 \\
\hline & & \multirow[t]{2}{*}{ Inter firm trust } & \multirow[t]{2}{*}{0.214} & Re-win percentage & 0.769 & 0.0737 \\
\hline & & & & $\begin{array}{l}\text { Length of inter firm } \\
\text { cooperation }\end{array}$ & 0.230 & 0.0221 \\
\hline \multirow[t]{4}{*}{ Cost } & \multirow[t]{4}{*}{0.201} & \multirow[t]{2}{*}{ Direct cost } & \multirow[t]{2}{*}{0.857} & Net price & 0.849 & 0.1462 \\
\hline & & & & Delivery cost & 0.150 & 0.0258 \\
\hline & & \multirow[t]{2}{*}{ Indirect cost } & \multirow[t]{2}{*}{0.142} & Ordering cost & 0.800 & 0.0228 \\
\hline & & & & Capital investment & 0.200 & 0.0057 \\
\hline \multirow[t]{6}{*}{ Quality } & \multirow[t]{6}{*}{0.176} & \multirow[t]{4}{*}{ Product quality } & \multirow[t]{4}{*}{0.857} & Customer rejecter & 0.370 & 0.0558 \\
\hline & & & & Warranty & 0.330 & 0.0498 \\
\hline & & & & ISO 9000 & 0.230 & 0.0347 \\
\hline & & & & Package & 0.050 & 0.0075 \\
\hline & & \multirow{2}{*}{$\begin{array}{l}\text { Manufacturing } \\
\text { quality }\end{array}$} & \multirow[t]{2}{*}{0.142} & Customer focus & 0.842 & 0.0210 \\
\hline & & & & $\begin{array}{l}\text { Top management } \\
\text { committee }\end{array}$ & 0.157 & 0.0039 \\
\hline \multirow[t]{3}{*}{ Delivery } & \multirow[t]{3}{*}{0.098} & \multirow{2}{*}{$\begin{array}{l}\text { Compliance } \\
\text { with due time }\end{array}$} & \multirow[t]{2}{*}{0.849} & Percentage late delivery & 0.750 & 0.0624 \\
\hline & & & & Delivery lead time & 0.250 & 0.0208 \\
\hline & & $\begin{array}{l}\text { Compliance } \\
\text { with quantity }\end{array}$ & 0.150 & Location & 1.000 & 0.0147 \\
\hline \multirow{13}{*}{$\begin{array}{l}\text { Manage- } \\
\text { ment and } \\
\text { organiza- } \\
\text { tion }\end{array}$} & \multirow[t]{13}{*}{0.045} & \multirow[t]{2}{*}{ Responsiveness } & \multirow[t]{2}{*}{0.422} & Urgent delivery & 0.400 & 0.0076 \\
\hline & & & & Quantity problem & 0.200 & 0.0038 \\
\hline & & \multirow[t]{2}{*}{ Dicipline } & \multirow[t]{2}{*}{0.268} & Honesty & 0.842 & 0.0102 \\
\hline & & & & Procedural complimant & 0.157 & 0.0019 \\
\hline & & \multirow[t]{2}{*}{ Envirement } & 0.112 & ISO 14000 certified & 0.769 & 0.0039 \\
\hline & & & & Waste management & 0.230 & 0.0012 \\
\hline & & Technical & 0.087 & Product range & 0.726 & 0.0028 \\
\hline & & capability & & Technical problem solving & 0.273 & 0.0011 \\
\hline & & Facility and & 0.069 & Infrastructure & 0.587 & 0.0018 \\
\hline & & capacity & & Machinery & 0.232 & 0.0007 \\
\hline & & & & Layout & 0.180 & 0.0006 \\
\hline & & Performance & 0.039 & Product Variety & 0.785 & 0.0014 \\
\hline & & history & & Product line & 0.214 & 0.0004 \\
\hline Financial & 0.030 & Manufacturing & 0.785 & Finance stability & 0.613 & 0.0144 \\
\hline & & fincial & & $\begin{array}{l}\text { Capital and banking } \\
\text { history }\end{array}$ & 0.236 & 0.0056 \\
\hline & & & & Profit/sale trends & 0.149 & 0.0035 \\
\hline & & Product & 0.214 & Discount & 0.694 & 0.0045 \\
\hline & & financial & & Turn-over & 0.185 & 0.0012 \\
\hline & & & & Interest on payment & 0.119 & 0.0008 \\
\hline & & & & & Total & 1.0000 \\
\hline
\end{tabular}

Table 4b. "Composite priority weights for sub sub-criteria".

Table 4 exhibits the local weights for each criterion in each level. The results show that in the second level of criteria, trust with local weight of $(0.448)$ had been prioritized as the first criteria followed by cost $(0.201)$, quality $(0.176)$, delivery (0.098), management and organization (0.045) and financial (0.030). The prioritized of sub criteria in the third level and sub-sub criteria in the fourth level 
also depend on the local weights. The global weights are calculated by multiplying the local weights with criteria, sub criteria and sub sub-criteria. As an example the calculations of the global weights of trust criteria are shown in following. The result of priority criteria's with local weights of each level is shown in Table 4.

\subsection{Step 4: Prioritize the order of criteria or sub criteria}

Having completed mathematical calculations, comparisons of criteria and allocating weights for each criterion in each level is performed. As indicated in the previous section (Priority weights for alternatives versus attribute and prediction priority), according to the results of each criterion weights define important criteria arrangement and classified in each level for selecting the supplier.

\begin{tabular}{|c|l|c|}
\hline Rank & \multicolumn{1}{|c|}{$\begin{array}{c}\text { Critical success factors (Sub sub- } \\
\text { criteria) }\end{array}$} & Global weights \\
\hline 1 & Trust between key men & 0.3517 \\
2 & Net price & 0.1462 \\
3 & Re-win percentage & 0.0737 \\
4 & Percentage late delivery & 0.0624 \\
5 & Customer rejecter & 0.0558 \\
6 & Warranty & 0.0498 \\
7 & ISO 9000 & 0.0347 \\
8 & Delivery cost & 0.0258 \\
9 & Ordering cost & 0.0228 \\
10 & Length of inter firm cooperation & 0.0221 \\
11 & Customer focus & 0.0210 \\
12 & Delivery lead time & 0.0208 \\
13 & Location & 0.0147 \\
14 & Finance stability & 0.0144 \\
15 & Honesty & 0.0102 \\
16 & Urgent delivery & 0.0076 \\
17 & Package & 0.0075 \\
18 & Capital investment & 0.0057 \\
19 & Capital and banking history & 0.0056 \\
20 & Discount & 0.0045 \\
21 & Top management committee & 0.0039 \\
22 & ISO 14000 certified & 0.0039 \\
23 & Quantity problem & 0.0038 \\
24 & Profit/sale trends & 0.0035 \\
25 & Product range & 0.0028 \\
26 & Procedural complimant & 0.0019 \\
27 & Infrastructure & 0.0018 \\
28 & Product Variety & 0.0014 \\
29 & Waste management & 0.0012 \\
30 & Technical problem solving & 0.0011 \\
31 & Turn-over & 0.0012 \\
32 & Interest on payment & 0.0008 \\
33 & Machinery & 0.0007 \\
34 & Layout & 0.0006 \\
35 & Product line & 0.0004 \\
\hline & & \\
\hline
\end{tabular}

Table 5. "Ranking of sub sub-critical".

After calculating the global weights of each sub sub-criteria of level 4 , the result is rearranged in descending order of priority, as shown in Table 5. The ranking list of 
critical success factors can be seen that trust and cost factors occupy the top-most ranking in the list, the top rank being the trust between key men (0.3517), followed by net price $(0.1462)$ and re-win percentage $(0.0737)$. The quality and delivery factors that are in the top ten ranking include percentage late delivery (0.0624), customer rejection (0.0558), warranty (0.0498), ISO9000 (0.0347), delivery cost (0.0258) and ordering cost (0.0228).

\subsection{Step 5: Measure supplier performance}

The main reason for adopting this method is the evaluation of supplier for a particular steel manufacturing company. After weighting the AHP model for determining priority weight for alternatives and testing the model, the third structured interview was designed and modifies. This interview collects the weightings of alternatives to identify the best supplier. In this step, to determine the priority weight for alternatives, the competitive rivals that are actually the suppliers who are supposed to be used for $A B C$ steel engineering company were compared. After finding the local weights of each alternative, the global weights of each alternative in each level can be calculated. The global weights evaluation of each alternative can be obtained through multiplying the global weights of sub subcriteria by the local weights of each alternative. The results and priority weight for each alternative are shown in Table 6.

In this step, software programming is applied for easily using and calculating the future supplier selection model. This software programming, which is for AHP supplier selection model, has been used for Microsoft visual studio 2005 (visual basic software). After allocating weights for the criteria in each level, there is need for mathematical calculations and comparisons on the verge of supplier selection, which is a difficult task for the purchasing manager of the company. In this study care is taken to facilitate the mentioned calculations on the last step of AHP provided to ease the calculations, and make the supplier selection easier and faster. In this case alternative questions will be asked from the purchasing manager, and after testing (C.R.), (C.I.) (Refer to section 2.8.4) the selection of the best supplier will be ranged. The primary values in this software are for filling up the point with local weights of level $2\left(x_{i}\right), 3\left(Y_{i}\right)$ and $4\left(S_{i}\right)$. The Question part is to type supplier comparison for each criterion. The Computation part had been used for calculating, evaluating, and testing (C.R.) and (C.I.) of each supplier. 
Selecting the suitable supplier also depends on priority weights. The three parts along with their details are shown in (Figure 3).

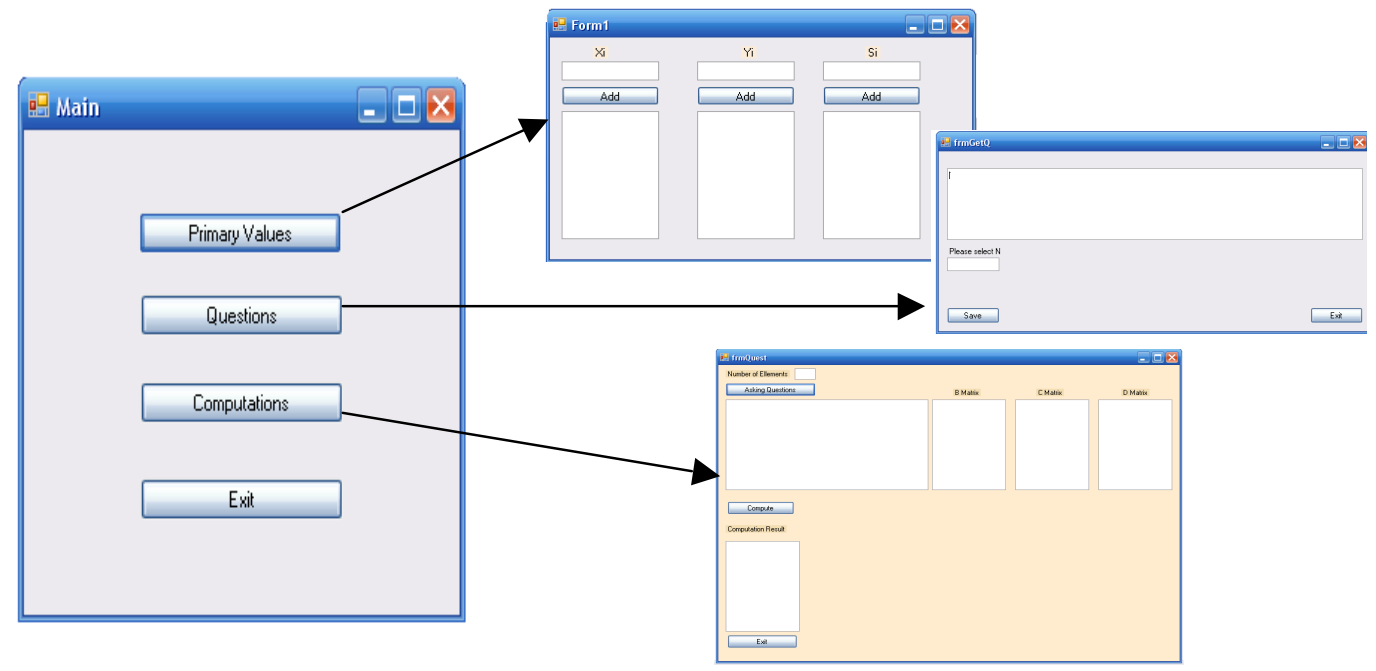

Figure 3. "The supplier selection program for ABC steel company".

\subsection{Step 6: Identify supplier priority and selection}

Based on the global priority, weights of each alternative can be evaluated and summarized. The summaries of overall attributes are shown in Table 6. It can be noted that among the four given suppliers, supplier " $C$ " has the highest weight. Therefore, it must be selected as the best supplier to satisfy the goals and objectives of the $A B C$ steel manufacturing company. Table 5 shows the final score of each supplier $s$ results and ranking. As can be seen, supplier Cs' score of $(0.395)$ is greater than the other three suppliers' scores such as supplier A (0.272), supplier B (0.192), and supplier D (0.139).

\section{Sensitivity analysis of result}

Sensitivity analysis identifies the impact of changes in the priority of criteria on the suppliers' performance and order quantities. After obtaining the initial solution with the given weights of the attributes, sensitivity analyses were carried out to explore the response of the overall utility of alternatives and to changes in the relative importance (weight) of each attribute or criterion. The sensitivity analyses are necessary because changing the importance of attributes or criteria requires different levels of trust, quality, cost, delivery, management and organization, 
financial and sourcing opportunities for the alternatives. A series of sensitivity analyses were conducted using the Expert Choice (EC) program.

\begin{tabular}{|c|c|c|c|c|c|c|c|c|c|}
\hline \multirow{2}{*}{$\begin{array}{l}\text { Critical success factors for supplier } \\
\text { selection }\end{array}$} & \multirow{2}{*}{$\begin{array}{l}\text { Global } \\
\text { weights }\end{array}$} & \multicolumn{2}{|c|}{ Supplier (A) } & \multicolumn{2}{|c|}{ Supplier (B) } & \multicolumn{2}{|c|}{ Supplier (C) } & \multicolumn{2}{|c|}{ Supplier (D) } \\
\hline & & $\begin{array}{c}\text { Local } \\
\text { weights }\end{array}$ & $\begin{array}{c}\text { Global } \\
\text { weights }\end{array}$ & $\begin{array}{c}\text { Local } \\
\text { weights }\end{array}$ & $\begin{array}{c}\text { Global } \\
\text { weights }\end{array}$ & $\begin{array}{c}\text { Local } \\
\text { weights }\end{array}$ & $\begin{array}{c}\text { Global } \\
\text { weights }\end{array}$ & $\begin{array}{c}\text { Local } \\
\text { weights }\end{array}$ & $\begin{array}{l}\text { Global } \\
\text { weights }\end{array}$ \\
\hline $\begin{array}{l}\text { Trust } \\
\text { Inter firm trust } \\
\text { Length of inter firm } \\
\text { cooperation }\end{array}$ & 0.0221 & $0.52=$ & 0.011 & $0.13=$ & 0.003 & $0.27=$ & 0.005 & $0.07=$ & 0.001 \\
\hline Re-win percentage & 0.0737 & $0.23=$ & 0.019 & $0.06=$ & 0.004 & $0.55=$ & 0.041 & $0.14=$ & 0.010 \\
\hline $\begin{array}{c}\text { Inter personal trust } \\
\text { Trust between key men }\end{array}$ & 0.3517 & $0.28=$ & 0.099 & $0.12=$ & 0.042 & $0.53=$ & 0.187 & $0.06=$ & 0.021 \\
\hline $\begin{array}{l}\text { Quality } \\
\text { Product quality } \\
\quad \text { Customer rejecter } \\
\end{array}$ & 0.0558 & $0.57=$ & 0.032 & $0.06=$ & 0.003 & $0.22=$ & 0.012 & $0.13=$ & 0.007 \\
\hline Warranty & 0.0498 & $0.59=$ & 0.029 & $0.06=$ & 0.003 & $0.19=$ & 0.009 & $0.14=$ & 0.007 \\
\hline ISO 9000 & 0.0347 & $0.25=$ & 0.008 & $0.25=$ & 0.008 & $0.25=$ & 0.008 & $0.25=$ & 0.008 \\
\hline Package & 0.0075 & $0.24=$ & 0.001 & $0.07=$ & 0.000 & $0.55=$ & 0.004 & $0.13=$ & 0.000 \\
\hline $\begin{array}{l}\text { Manufacturing quality } \\
\text { Top management committee }\end{array}$ & 0.0039 & $0.44=$ & 0.001 & $0.07=$ & 0.000 & $0.33=$ & 0.001 & $0.14=$ & 0.000 \\
\hline Customer focus & 0.0210 & $0.29=$ & 0.006 & $0.06=$ & 0.001 & $0.51=$ & 0.010 & $0.12=$ & 0.002 \\
\hline $\begin{array}{l}\text { Cost } \\
\text { Direct cost } \\
\text { Delivery cost }\end{array}$ & 0.0258 & $0.12=$ & 0.003 & $0.28=$ & 0.007 & $0.52=$ & 0.013 & $0.07=$ & 0.001 \\
\hline Net price & 0.1462 & $0.15=$ & 0.023 & $0.38=$ & 0.055 & $0.38=$ & 0.055 & $0.07=$ & 0.011 \\
\hline $\begin{array}{c}\text { Indirect cost } \\
\text { Ordering cost } \\
\end{array}$ & 0.0228 & $0.17=$ & 0.003 & $0.47=$ & 0.010 & $0.28=$ & 0.006 & $0.07=$ & 0.001 \\
\hline Capital investment & 0.0057 & $0.13=$ & 0.001 & $0.48=$ & 0.002 & $0.31=$ & 0.001 & $0.06=$ & 0.000 \\
\hline $\begin{array}{l}\text { Delivery } \\
\text { Compliance with due time } \\
\text { Delivery lead time }\end{array}$ & 0.0208 & $0.07=$ & 0.005 & $0.29=$ & 0.006 & $0.50=$ & 0.010 & $0.12=$ & 0.002 \\
\hline Percentage late delivery & 0.0624 & $0.27=$ & 0.016 & $0.12=$ & 0.007 & $0.07=$ & 0.004 & $0.53=$ & 0.033 \\
\hline $\begin{array}{c}\text { Compliance with quantity } \\
\text { Location }\end{array}$ & 0.0147 & $0.11=$ & 0.001 & $0.06=$ & 0.000 & $0.27=$ & 0.002 & $0.53=$ & 0.007 \\
\hline $\begin{array}{r}\text { Management and organization } \\
\text { Responsiveness } \\
\text { Quantity problem }\end{array}$ & 0.0038 & $0.14=$ & 0.001 & $0.07=$ & 0.000 & $0.53=$ & 0.001 & $0.24=$ & 0.000 \\
\hline Urgent delivery & 0.0076 & $0.56=$ & 0.004 & $0.06=$ & 0.000 & $0.14=$ & 0.002 & $0.22=$ & 0.001 \\
\hline $\begin{array}{c}\text { Discipline } \\
\text { Honesty } \\
\end{array}$ & 0.0102 & $0.16=$ & 0.001 & $0.15=$ & 0.001 & $0.23=$ & 0.000 & $0.07=$ & 0.000 \\
\hline Procedural complimant & 0.0019 & $0.49=$ & 0.000 & $0.12=$ & 0.000 & $0.30=$ & 0.000 & $0.07=$ & 0.000 \\
\hline $\begin{array}{l}\text { Environment } \\
\text { ISO } 14000 \text { certified }\end{array}$ & 0.0039 & $0.25=$ & 0.001 & $0.25=$ & 0.000 & $0.25=$ & 0.000 & $0.25=$ & 0.000 \\
\hline Waste management & 0.0012 & $0.55=$ & 0.000 & $0.15=$ & 0.000 & $0.07=$ & 0.000 & $0.22=$ & 0.000 \\
\hline $\begin{array}{l}\text { Technical capability Product } \\
\text { range }\end{array}$ & 0.0028 & $0.11=$ & 0.000 & $0.57=$ & 0.001 & $0.24=$ & 0.000 & $0.06=$ & 0.000 \\
\hline Technical problem solving & 0.0011 & $0.38=$ & 0.000 & $0.40=$ & 0.000 & $0.09=$ & 0.000 & $0.11=$ & 0.000 \\
\hline $\begin{array}{c}\text { Facility and capacity } \\
\text { Machinery }\end{array}$ & 0.0007 & $0.30=$ & 0.000 & $0.49=$ & 0.000 & $0.14=$ & 0.000 & $0.05=$ & 0.000 \\
\hline Infrastructure & 0.0018 & $0.49=$ & 0.000 & $0.06=$ & 0.000 & $0.13=$ & 0.000 & $0.29=$ & 0.000 \\
\hline Layout & 0.0006 & $0.51=$ & 0.000 & $0.06=$ & 0.000 & $0.15=$ & 0.000 & $0.27=$ & 0.000 \\
\hline $\begin{array}{r}\text { Performance history } \\
\text { Product line }\end{array}$ & 0.0004 & $0.23=$ & 0.000 & $0.57=$ & 0.000 & $0.14=$ & 0.000 & $0.05=$ & 0.000 \\
\hline Product Variety & 0.0014 & $0.28=$ & 0.000 & $0.52=$ & 0.000 & $0.13=$ & 0.000 & $0.05=$ & 0.000 \\
\hline $\begin{array}{l}\text { Financial } \\
\text { Manufacturing finical } \\
\text { Profit/sale trends }\end{array}$ & 0.0035 & $0.05=$ & 0.000 & $0.22=$ & 0.000 & $0.58=$ & 0.002 & $0.13=$ & 0.000 \\
\hline Finance stability & 0.0144 & $0.05=$ & 0.000 & $0.26=$ & 0.003 & $0.13=$ & 0.001 & $0.54=$ & 0.007 \\
\hline Capital and banking history & 0.0056 & $0.31=$ & 0.001 & $0.10=$ & 0.000 & $0.06=$ & 0.000 & $0.51=$ & 0.002 \\
\hline $\begin{array}{l}\text { Product financial } \\
\text { Interest on payment }\end{array}$ & 0.0008 & $0.05=$ & 0.000 & $0.11=$ & 0.000 & $0.28=$ & 0.000 & $0.54=$ & 0.000 \\
\hline Discount & 0.0045 & $0.28=$ & 0.001 & $0.14=$ & 0.000 & $0.28=$ & 0.001 & $0.28=$ & 0.001 \\
\hline Turn-over & 0.0012 & $0.27=$ & 0.000 & $0.14=$ & 0.000 & $0.51=$ & 0.000 & $0.06=$ & 0.000 \\
\hline Total score & & 0.2726 & & 0.1920 & & 0.3950 & & 0.1397 & \\
\hline
\end{tabular}

Table 6. "Summarizes of priority weights of each alternative" 
Performance Sensitivity Analysis (PSA) of Expert Choice (EC), shown in (Figure 4), represents the variation of suppliers' ranking to changes in each criterion. It illustrates the ratio of each alternative's weight percentage to criteria weights. The results show that in trust criteria supplier $C$ ranked in the highest grade and supplier $\mathrm{D}$ ranked the lowest score. It can be seen that in delivery criteria supplier $D$ has the highest score and supplier $B$ has the lowest score. This dynamic performance analysis tool is configurable according to the important criteria's for purchasing mangers in their projects. As an example, (Figure 5) illustrates that if the quality and delivery criteria are critical in a project, they can be set to $40 \%$ and in consequence the suppliers' ranking is changed to supplier A followed by supplier $D, C$ and $B$.

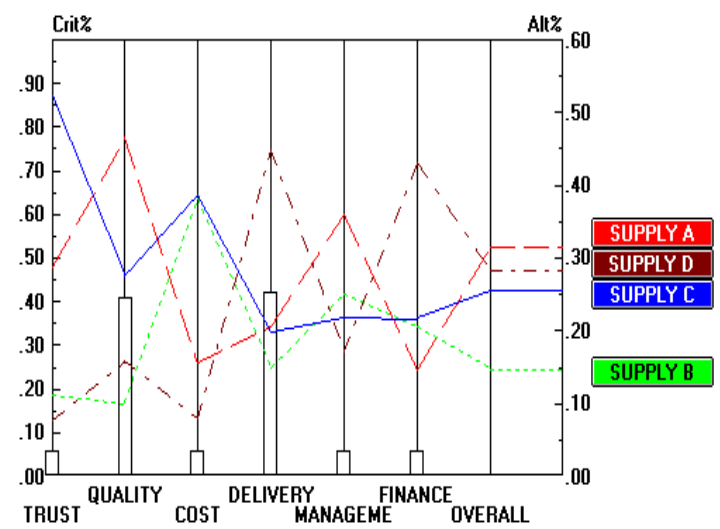

Figure 4. "Performance sensitivity analysis on supplier selection".

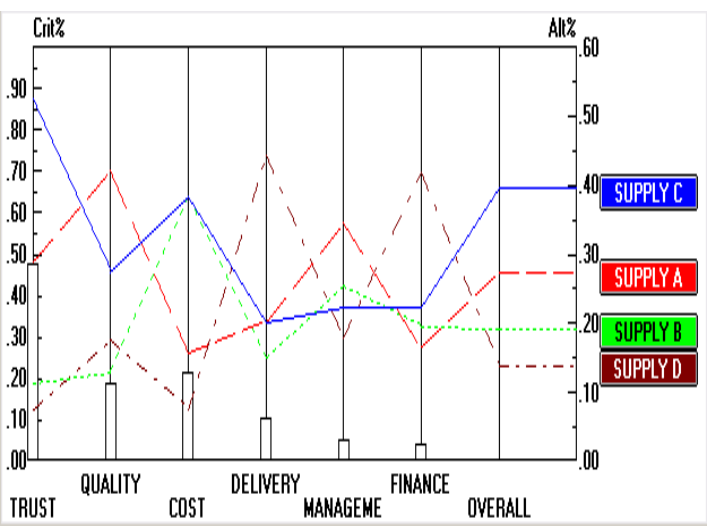

Figure 5. "Performance sensitivity analysis on supplier selection after change the score of quality and delivery criteria".

Gradient Sensitivity Analysis (GSA) of Expert Choice (EC), which is shown in (Figure 6 ), represents the variation of suppliers' ranking to changes in delivery criteria. It illustrates that if the delivery criterion, which is $9.8 \%$, increases to $23.7 \%$ or decreases to $0 \%$, the suppliers' ranking do not change. In the second area, if the weight of delivery is between $23.9 \%$ and $43.7 \%$ the ranking of supplier will change to this order: supplier $C$ following by supplier $A, D$ and $B$. The changes of the delivery criteria weighting in the rest of the areas are brought in Table 7. It can be seen that within the five following areas of GSA the suppliers' ranking were not sensitive as shown in Table 7. 


\begin{tabular}{|c|c|c|}
\hline Area & Delivery criteria & Suppliers' ranking \\
\hline 1 & $0.00 \%-23.9 \%$ & $S_{C}>S_{A}>S_{B}>S_{D}$ \\
\hline 2 & $23.9 \%-43.7 \%$ & $S_{C}>S_{A}>S_{D}>S_{B}$ \\
\hline 3 & $43.7 \%-57.7 \%$ & $S_{C}>S_{D}>S_{A}>S_{B}$ \\
\hline 4 & $57.7 \%-98.9 \%$ & $S_{D}>S_{C}>S_{A}>S_{B}$ \\
\hline 5 & $98.9 \%-100 \%$ & $S_{D}>S_{A}>S_{C}>S_{B}$ \\
\hline
\end{tabular}

Table 7. "Classifies suppliers' ranking within five areas".

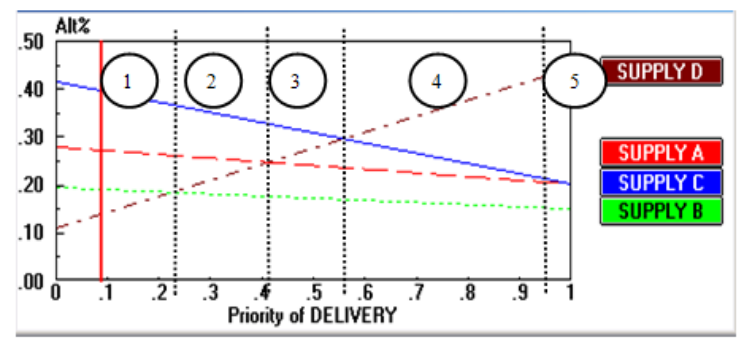

Figure 6. "Gradient Sensitivity of supplier's performance on delivery".

\section{Conclusions and future work}

The issues of supplier selection have attracted the interest of researchers since 1960s, and many researches in this area have evolved. Continuing the previous works in supplier selection area, the work has successfully achieved its objectives.

The main contribution of the work was the identification of the important criteria for supplier selection process. The criteria found were Trust between key men, followed by net price and re-win percentage as can be seen in Table 4. This achievement covered the first objective of the research. The second contribution was a development of a multi-criteria decision model for evaluation and selection which is used for supplier selection in ABC steel company as illustrated in Figure 2. The model for supplier evaluation and selection were successfully developed by using AHP method dedicated for steel manufacturing company. The four-level of AHP model is assessing decision-makers to identify and evaluate the supplier selection. These achievements covered the second objective of the research. Finally, the developed model is tested on four supplier selection problems. The results show the models are able to assist decision-makers to examine the strengths and weaknesses of supplier selection by comparing them with appropriate criteria, sub-criteria and sub sub-criteria. Furthermore, the model is 
applicable to any supplier selection problem in $A B C$ steel manufacturing company in Malaysia. In addition, the proposed AHP model is significantly effective in decision making. With the use of AHP model software, the results can be transferred to a spreadsheet for easy computations and it is easier to identify and evaluate suppliers to arrive to a consensus decision. The works that have been carried out, can be reused to identify any supplier ranking case, in order to evaluate and compare other new future suppliers with the consideration both quantity and quality criteria in $A B C$ steel manufacturing company.

In order to pursue with this inquisition and survey in its being effective in all aspects of manufacturing, the following recommendations were suggested:

- Considering the abundance of suppliers in all levels of industry and their ramifications throughout the whole country of Malaysia the process of supplier selection priority based on the quantity and quality criteria should be carried out in all industries and divisions in order to select the ideal supplier.

- In order to have a more reliable result, it is suggested that in future group AHP or Fuzzy AHP be applied to guide decision making toward a more constructive and consolidated plan. To comply with this method, questionnaires are prepared which have to be taught to the related and evolved members to enable them to fill them out correctly and accurately to get optimum advantages and results. Therefore training classes for the participant members, involved in decision making, are highly recommended in order to upgrade their know-ledge in using the sophisticated technique of "AHP". Considering the simplicity of this technique, the involved members can gain the basic and essential context of this method along with being cognizant of the questionnaires. Afterwards, the group will be able to analyze the given data, inputs. Although this method is utterly beneficial and useful for paving the road for the group to make constructive decisions, it has some handicaps and faults which can be alleviated and compensated through the mathematical methods indulged in it.

- In future this inquisition method can be generalized to all steel manufacturing plants and industries throughout Malaysia to facilitate the supplier selection. 
- Another supplier selection model that could be addressed in the future is selecting the suitable supplier's in order to purchase the new advanced manufacturing technology (AMT) such as Robot technology.

\section{References}

Akarte, M.M. (2001). Web based casting supplier evaluation using analytic hierarchy process. Journal of the Operational Research Society 52 (5): 511-522.

Amid, A., S. H. Ghodsypour \& C. O'brien. (2006). Fuzzy multi objective linear model for supplier selection in a supply chain. Production Economics 104: 394-407.

Bello, M. J. S. (2003). A case study approach to the supplier selection process. Master of engineering. Management Systems Engineering, University of Puerto rico mayaguez campus.

Bross, M. E. \& G. Zhao. (2004). Supplier selection process in emerging markets The case study of Volvo Bus Corporation in China. Master Thesis. School of Economics and Commercial Law. Göteborg University.

Chen-Tung, C., L. Ching-Torng \& S. F. Huanget. (2006). A fuzzy approach for supplier evaluation and selection in supply chain management. Production Economics 102: 289-301.

Davidrajuh, R. (2000). Automating Supplier Selection Procedures. Doctor of Engineering Degree Norwegian University of Science and Technology (NTNU), Narvik Institute of Technology Narvik, Norway.

Dickson, G. W. (1966). An analysis of vendor selection systems and decisions. journal of Purchasing 2(1): 5-17.

Dulmin, R. \& V. Mininno. (2003). Supplier selection using a multi-criteria decision aid method. Journal of Purchasing and Supply Management 9: 177-187.

Dyer, J. H., D. S. Cho \& W. Chu. (1996). Strategic supplier segmentation: A model for managing suppliers in the 21st centery. Philadelphia, University of Pemsylvania. 
Ghodsypour, S. H. \& C. O'Brien. (1998). A decision support system for supplier selection using an integrated analytical hierarchy process and linear programming. International Journal of Production Economics 56-67: 199-212.

Handfield, R., S. V. Walton \& Sroufe, R. (2002). Applying environmental criteria to supplier assessment: A study in the application of the Analytical Hierarchy Process. European Journal of Operational Research 141: 70-87.

Li, C. C., Y. P. Fun \& Hung, J.S. (1997). "A new measure for supplier performance evaluation." IIE Transactions 29: pp.753-758.

Liu, F.H. F.\& H. L. Hai. (2005). The voting analytic hierarchy process method for selecting supplier. International Journal of Production Economics 97(3): 308-317.

Omkarprasad, S. V. \& S. Kumar. (2006). Analytic hierarchy process: An overview of applications. European Jurnal of Operational Research 169: 1-29.

Przewosnik, D., I. Smeja \& U. Tenschertet. (2006). Supplier Selection - A Study of the Supplier Selection Process within the Sporting Goods Manufacturing Industry. Master Thesis:Master Programme in Logistics Management.School of Management and Economy (Vaxjo).

Saaty, T. (1980). The Analytic Hierarchy Process. N. Y. McGraw-Hill.

Tam, M. C. Y. \& V. M. R. Tummala. (2001). An Application of the AHP in vendor selection of a telecommunications system. Omega 29(2): 171-182.

Tullous, R. \& J. M. Munson. (1991). Trade-Offs Under Uncertainty: Implications for Industrial Purchasers. International Journal of Purchasing and Materials Management 27(3): 24-31.

Vargas, L. (1990). An overview of analytic hierarchy process: Its applications. European Journal of Operational Research 48(1): 2-8.

Weber, C. A., J. r. Current \& W. C. Benton. (1991). Vendor selection criteria and methods. European Jurnal of Operational Research 50: 2-18.

Yahya, S. \& B. Kingsman. (1999). Vendor rating for an entrepreneur development programme: a case study using the analytic hierarchy process method. Journal of the Operational Research Society 50: 916-930. 
Yusuff, R. d., K. PohYee \& M.S.J. Hashmi. (2001). A preliminary study on the potential use of the analytical hierarchical process (AHP) to predict advanced manufacturing technology (AMT) implementation. Robotics and Computer Integrated Manufacturing 17: 421-427.

Yu, X. \& S. Jing. (2004). A Decision Model for Supplier Selection Considering Trust. Chinese Business Review 3(6): 15-20.

Zhang, Z., J. Lei, N. Cao, K. To \& K. Ng. (2003). Evolution of Supplier Selection Criteria and Methods. European Journal of Operational Research 4(1): 335-342.

Article's contents are provided on a Attribution-Non Commercial 3.0 Creative commons license. Readers are allowed to copy, distribute and communicate article's contents, provided the author's and Journal of Industrial Engineering and Management's names are included. It must not be used for commercial purposes. To see the complete license contents, please visit http://creativecommons.org/licenses/by-nc/3.0/. 